\title{
SECRETOS EMPRESARIALES Y DERECHO DE ACCESO A LA INFORMACIÓN AMBIENTAL
}

\section{BUSINESS SECRETS AND RIGHT OF ACCESS TO ENVIRONMENTAL INFORMATION}

\author{
ÁlvARO GÓMEZ EXPÓSITO \\ Abogado en Baño León Abogados / Doctorando en Derecho Administrativo del \\ Grupo de investigación LEGAMBIENTAL-UV \\ Universidad de Valencia \\ agomez@banoleon.com
}

Fecha de recepción: 31 de agosto de 2021 / Fecha de aceptación: 15 de noviembre de 2021

RESUMEN: El presente trabajo analiza el secreto empresarial como límite al derecho de acceso a la información ambiental reconocido en la Ley 27/2006, de 18 de julio. Dicho análisis trata de determinar, en primer lugar, qué debe entenderse por "datos confidenciales de carácter comercial o industrial" a la luz de la Ley $1 / 2019$, de 20 de febrero, de Secretos empresariales, que ha venido a clarificar por fin dicho concepto. En segundo lugar, se ofrecen los criterios que la Administración debe considerar a la hora de decidir sobre el acceso a la información "sensible" de las empresas.

RESUM: El present treball analitza el secret empresarial com a límit al dret d'accés a la informació ambiental reconegut en la Llei 27/2006, de 18 de juliol. Aquest anàlisi tracta de determinar, en primer lloc, què ha d'entendre's per "dades confidencials de caràcter comercial o industrial" a la llum de la Llei 1/2019, de 20 de febrer, de Secrets empresarials, que ha vingut a aclarir per fi aquest concepte. En segon Iloc, s'ofereixen els criteris que l'Administració ha de 
considerar a l'hora de decidir sobre l'accés a la informació "sensible" de les empreses.

ABSTRACT: This work analyzes business secrets as a limit to the right of access to environmental information, recognized in Right of Access to Environmental Information Act 27/2006. This analysis tries to determine, on the one hand, what should be understood by "confidential data of a commercial or industrial nature", taking into account the Business Secrets Act 1/2019, which has finally clarified the concept. On the other hand, the criteria that the Administration must consider when deciding on access to "sensitive" information of companies are offered.

PALABRAS CLAVE: Derecho de acceso - Medio ambiente - Secreto empresarial.

PARAULES CLAU: Dret d'accés - Medi ambient - Secret empresarial.

KEYWORDS: Right of access - Environment - Business secret.

SUMARIO: I. PLANTEAMIENTO. II. EL IMPRECISO TRATAMIENTO NORMATIVO DE LA "INFORMACIÓN SENSIBLE" COMO EXCEPCIÓN AL DERECHO DE ACCESO. III. LOS DATOS CONFIDENCIALES DE CARÁCTER COMERCIAL E INDUSTRIAL: UNA APROXIMACIÓN AL SECRETO EMPRESARIAL. 3.1. La información sensible en la legislación ambiental. 3.2. EI concepto de secreto empresarial en la Ley 1/2019. 3.3. Distinción con los derechos de propiedad industrial. IV. LA DENEGACIÓN DEL ACCESO COMO MECANISMO DE TUTELA: PRESUPUESTOS. 4.1. LA PROTECCIÓN DE INTERESES ECONÓMICOS LEGÍTIMOS. 4.2. Reconocimiento legal de la confidencialidad. 4.3. Divulgación perjudicial: Ponderación de los intereses en conflicto. V. CONCLUSIONES. VI. BIBLIOGRAFÍA.

\section{PLANTEAMIENTO}

La protección del medio ambiente permite a los poderes públicos imponer límites y condiciones a los derechos de las empresas (art. 45 CE) ${ }^{1}$. Dicha intervención se presenta mediante diversas técnicas como las concesiones, autorizaciones, comunicaciones o declaraciones responsables, según el tipo de actividad y su grado de lesividad ambiental.

\footnotetext{
${ }^{1}$ Entre otras, SSTC 64/1982, de 4 de noviembre; y, 113/1994, de 14 de abril.
} 
Las empresas se ven obligadas, en suma, a proporcionar a las Administraciones Públicas cantidades ingentes de información sobre sus instalaciones y procesos productivos. Información que generalmente incluye datos "sensibles" que preferirían mantener en secreto ${ }^{2}$. No obstante, el reconocimiento del derecho de acceso a la información ambiental lo impide ${ }^{3}$.

La Ley 27/2006, de 18 de julio, por la que se regulan los derechos de acceso a la información, de participación pública y de acceso a la justicia en materia de medio ambiente (en adelante, Ley 27/2006) ${ }^{4}$, obliga a la Administración a difundir información sobre el medioambiente y reconoce el derecho de los ciudadanos a acceder a la misma, con la finalidad última de garantizar que disponen de los datos necesarios para participar en la toma de decisiones o, incluso, impugnarlas ante los tribunales 5 . Todo ello en aras de una administración más transparente, justa, participativa y democrática.

\footnotetext{
2 Sainz Moreno, F., "Secreto e información en el Derecho Público", en Martín-Retortillo BAQUER, S., Estudios sobre la Constitución Española. Homenaje al profesor Eduardo García de Enterría, vol. 3, Civitas, 1991, pág. 2972.
}

3 El reconocimiento del derecho de acceso a la información tuvo una de sus primeras manifestaciones en el Derecho ambiental. Como ha destacado ScHMIDT-ASSMANN, E., La teoría general del derecho administrativo como sistema: objeto y fundamentos de la construcción sistemática, Marcial Pons, 2003, págs. 11 y ss., el Derecho ambiental está marcando la línea de evolución del Derecho administrativo. El derecho de acceso a la información en poder de la Administración, en general, se recoge también en el Derecho europeo (art. 15.3 TFUE, íntimamente ligado con los arts. 11 TUE y 42 CDFUE). En el Derecho español, la Ley 19/2013, de 9 de diciembre, de transparencia, acceso a la información pública y buen gobierno, pretende reforzar la transparencia y garantizar este derecho de los ciudadanos. Sobre la articulación entre estos dos regímenes de acceso véase CASADO CASADO, L., "El acceso a la información ambiental en España: situación actual y perspectivas de futuro", Revista Aragonesa de Administración Pública, oㅜ 53, 2019, págs. 99 y ss.

${ }^{4}$ Esta norma traspuso las Directivas 2003/4/CE del Parlamento Europeo y del Consejo, de 28 de enero de 2003, sobre el acceso del público a la información ambiental; y, 2003/35/CE del Parlamento Europeo y del Consejo, de 26 de mayo de 2003, por la que se establecen medidas para la participación del público en determinados planes y programas relacionados con el medio ambiente; que derogaron la Directiva 90/313/CEE. Estas normas suponen el cumplimiento de los compromisos asumidos en el Convenio de Aarhus sobre "El acceso a la información, la participación pública en la toma de decisiones y el acceso a la justicia en asuntos ambientales". Véase KRAMER, L., "Citizens rights and administrations' duties in environmental matters: 20 years of the Aarhus Convention", Revista Catalana de Dret Ambiental, № 9, 2018, págs. 5 a 11.

${ }^{5}$ Como afirma TRIAS Prats, B., "Veinticinco años de acceso a la información ambiental en Italia: de la ley 349/1986 a la Directiva Inspire", Revista de Administración Pública, № 188, 2012, pág. 395, "no constituye un fin en sí mismo, sino más bien un instrumento orientado a la consecución de una multiplicidad de objetivos inmediatos (transparencia, control, participación, etcétera). $Y$ por encima de todo eso, más aun, orientado a la consecución del objetivo último y principal: la protección del medio ambiente". 
El derecho de acceso a la información ambiental en poder de las Administraciones Públicas se reconoce en unos términos muy amplios ${ }^{6}$.

La conjunción de la obligación de las empresas de aportar información a la Administración y el reconocimiento del derecho a acceder a la misma sin necesidad de justificar la petición ${ }^{7}$ puede ocasionar problemas en la práctica ${ }^{8}$.

El legislador, consciente del conflicto, permite a la Administración denegar la información cuando deba prevalecer otro de los intereses, como la defensa nacional, la seguridad pública, las relaciones internacionales, o los datos confidenciales de carácter comercial o industrial (art. 13 de la Ley 27/2006) ${ }^{9}$.

El presente trabajo analiza el poder de la Administración para denegar el acceso a la información basado en la confidencialidad de los datos empresariales establecido en el art. 13.2.d) de la Ley 27/2006.

\section{EL IMPRECISO TRATAMIENTO NORMATIVO DE LA “INFORMACIÓN SENSIBLE" COMO EXCEPCIÓN AL DERECHO DE ACCESO}

El art. 13.2.d) de la Ley 27/2006 permite denegar las solicitudes de información para proteger datos de carácter comercial e industrial, con fundamento en el tradicional principio de protección de los secretos comerciales ${ }^{10}$. Este principio general, íntimamente ligado a la libertad de empresa (art. 38 CE) y al derecho de

\footnotetext{
6 Véase la definición de "información ambiental" de la Ley 27/2006 (art. 2.3); así como las SSTJUE de 16 de diciembre de 2011 (asunto C-266/09) y de 14 de febrero de 2012 (asunto C204/09). Como apunta CASADO CASADO, L., "El acceso a la información ambiental en España: situación...", op.cit., pág. 116, son muchos los problemas que se siguen planteando a la hora de determinar si este concepto incluye información de carácter técnico o económico-financiero.

7 STJ de Castilla-La Mancha de 26 de marzo de 2007. Sobre esta cuestión, GARCíA URETA, A., "Perspectivas sobre el derecho de acceso a la información sobre el ambiente: un repaso a la Directiva 90/313/CEE", Revista de Derecho Ambiental, no 13, 1994, pág. 141, afirma que la Administración únicamente podría exigir la justificación de un interés legítimo al solicitante respecto a aquella información que no fuera estrictamente de carácter ambiental.

8 Revuelta Pérez, I., "La participación de los ciudadanos en el control integrado de la contaminación", en ESTEVE PARDO, J. (coord.), Derecho del medio ambiente y de la Administración Local, Fundación Democracia y Gobierno Local, 2006, pág. 81.

9 CASADO CASADO, L., "El derecho de acceso a la información ambiental a través de la jurisprudencia", Revista de Administración Pública, № 178, 2009, págs. 281 a 322, para un análisis jurisprudencial de estas excepciones.

${ }^{10}$ Este principio tiene una larga tradición en nuestro derecho y ha sido reconocido en el derecho europeo por una consolidada jurisprudencia del TJUE, entre otras, en las Sentencias de 24 de junio de 1986 (asunto C-53/85), de 19 de mayo de 1994 (asunto C-36/92), de 14 de febrero de 2008 (asunto C-450/06), y de 29 de marzo de 2012 (asunto C-1/11); así como la STGUE de 16 de diciembre de 2010 (asunto T-19/07).
} 
propiedad (art. $33 \mathrm{CE})^{11}$, protege el interés concurrencial de los operadores económicos. La tutela del secreto se relaciona con la denominada "moral comercial", es decir, con el deber de respeto entre los operadores económicos para garantizar prácticas comerciales basadas en la buena fe, que impiden utilizar ilegítimamente información ajena ${ }^{12}$. También salvaguarda, en lo que aquí interesa, la confianza de las empresas en la Administración ${ }^{13}$.

A pesar de su importancia y de las complejidades que entraña su aplicación, estamos ante un límite al derecho de acceso que ha sido objeto de escasa atención por la doctrina y la jurisprudencia ${ }^{14}$.

La simple lectura del art. 13.2.d) de la Ley 27/2006 evidencia dos problemas básicos:

En primer lugar, es necesario definir la expresión "datos confidenciales de carácter comercial o industrial", utilizada en el precepto. Ello exige establecer requisitos que clarifiquen esta categoría jurídica, naturalmente abstracta y cambiante, y distinguirla de otras figuras afines que puedan crear confusión.

En segundo lugar, es necesario concretar los requisitos que exige el precepto para denegar la solicitud de información, dada su mejorable redacción.

\footnotetext{
${ }^{11}$ Un sector doctrinal entiende que los secretos empresariales son también una extensión natural del derecho a la intimidad (SANTAMARíA PASTOR, J.A., "La actividad de la Administración", en Comentario sistemático a la Ley de Régimen Jurídico de las Administraciones Públicas y del Procedimiento Administrativo Común, Carperi, 1993, pág. 142; y, QUERALT JIMÉNEZ, J.J., "La inviolabilidad domiciliaria y los controles administrativos. Especial referencia a la de las empresas", Revista Española de Derecho Constitucional, № 30, 1990, págs. 41 y ss.). Sin embargo, otro sector (FERNÁNDEZ RAMOS, S., El derecho de acceso a los documentos administrativos, Marcial Pons, 1997, pág. 519) se opone a vincular el art. 18 CE a los secretos comerciales e industriales debido a los problemas propios de reconocer el derecho a la intimidad de las personas jurídicas (entre otros, RUIz MIGUEL, C., La configuración constitucional del derecho a la intimidad, Tecnos, 1995, pág. 116).

12 Carbajo Cascón, F., "Violación de secretos, inducción y aprovechamiento de la infracción contractual e infracción de normas", en GARCíA-CruCES GonZÁlEZ, J. (coord.), Tratado de Derecho de la Competencia y de la Publicidad, Tomo II, Tirant lo Blanch, 2014, pág. 1541.

${ }^{13}$ Como afirma Fernández Ramos, S., El derecho de acceso a los documentos..., op.cit, pág. 521, "se trata también de preservar las necesarias relaciones de confianza entre el sector privado y la Administración, pues de lo contrario podría comprometerse la capacidad misma de la Administración de obtener la información indispensable para el cumplimiento de sus funciones".

${ }^{14}$ FERnÁNDEZ RAMOS, S., El derecho de acceso a los documentos..., op.cit., pág. 518; y, RAZQUIN LIZARRAGA, M.M., La confidencialidad de los datos empresariales en poder de las Administraciones Públicas (Unión Europea y España), lustel, 2013, pág. 319.
} 
El objetivo del presente trabajo es clarificar ambas cuestiones, para facilitar la aplicación de esta excepción por parte de la Administración.

\section{LOS DATOS CONFIDENCIALES DE CARÁCTER COMERCIAL E INDUSTRIAL: UNA APROXIMACIÓN AL SECRETO EMPRESARIAL}

\section{La información sensible en la legislación ambiental}

La primera cuestión es determinar qué debe entenderse por "datos confidenciales de carácter comercial e industrial". La Ley 27/2006 utiliza esta expresión para referirse a aquella información relevante que merece ser protegida por referirse al ámbito secreto de las empresas.

Conviene, previamente, analizar el tratamiento de esta información en la legislación ambiental. Junto al término utilizado por el art. 13.2.d) de la Ley 27/2006; el Texto Refundido de la Ley de Prevención y Control Integrados de la Contaminación de 2016 utiliza la expresión "datos que gocen de confidencialidad" (art. 12.1.d); y, la Ley 21/2013, de Evaluación Ambiental, utiliza indistintamente "confidencialidad de las informaciones", "secreto comercial" y "secreto industrial" (art. 15).

En el ámbito europeo, la derogada Directiva 90/313 utilizaba la expresión "secretos comerciales e industriales" (art. 3), y la vigente Directiva 2003/4 alude a "datos comerciales e industriales". El Reglamento 1367/2006, relativo a la aplicación de las disposiciones del Convenio de Aarhus a las Instituciones y Organismos Comunitarios, remite al Reglamento 1049/2001, que utiliza el término "intereses comerciales"; igual que el Reglamento 1907/2006, relativo al registro, la evaluación y la restricción de sustancias y preparados químicos (en adelante, Reglamento REACH) (art. 118.2).

Observamos que, pese a ser expresiones similares, no existe un consenso sobre cómo designar a este tipo de información. Además, existen otras formas de nombrar a esta figura, como, por ejemplo, el término anglosajón "know-how"15.

\footnotetext{
${ }^{15}$ Véase, la Voz "know-how", en el Diccionario del español jurídico de la Real Academia Española de la Lengua, que transcribe la definición del Reglamento 240/96 de la Comisión, de 31 de enero de 1996, relativo a la aplicación del apartado 3 del artículo 85 del Tratado a determinadas categorías de acuerdos de transferencia de tecnología, como un "conjunto de informaciones técnicas secretas, sustanciales e identificadas de forma apropiada" (art. 10). Sobre esta cuestión puede verse Gómez SEGADE, J.A., El secreto industrial (know-how). Concepto y protección,
} 
Esta imprecisión terminológica no es un problema específico del Derecho ambiental, sino que ha sido la tónica general en el Ordenamiento jurídico español ${ }^{16}$.

Hasta la aprobación la Ley 1/2019, de 20 de febrero, de Secretos Empresariales, que traspone la Directiva 2016/943 del Parlamento Europeo y del Consejo, de 8 de junio de 2016, relativa a la protección de los conocimientos técnicos y la información empresarial no divulgados (secretos comerciales) contra su obtención, utilización y revelación ilícitas, no ha existido una definición legal de esta institución ${ }^{17}$.

Esta diversidad terminológica genera inseguridad jurídica, como puso de manifiesto la doctrina más autorizada ${ }^{18}$. No obstante, la cuestión debe centrarse en que concurran los requisitos que a continuación se expondrán. En ese caso, y con independencia del término que se utilice, se estará ante lo que la doctrina mercantilista ha acuñado como "secreto empresarial".

\section{El concepto de secreto empresarial en de la Ley 1/2019}

El art. 1 de la Ley 1/2019 define el secreto empresarial como cualquier información o conocimiento que sea secreto, tenga valor comercial y haya sido objeto de medidas de protección por parte de su titular ${ }^{19}$. La definición legal se

Tecnos, 1974, págs. 159 a 163; y MASSAGUER FUENTES, J., El contrato de licencia de know-how, Librería Bosch, 1989, págs. 15 y 16.

${ }^{16}$ Gómez SEGADE, J.A., El secreto industrial..., op.cit., pág. 50; y SUÑOL LUCEA, A., El secreto empresarial: un estudio del artículo 13 de la Ley de Competencia Desleal, Civitas ThomsonReuters, 2009, págs. 105 y ss.

${ }^{17}$ Excepción hecha del art. 39.2 del Acuerdo sobre Aspectos de los Derechos de Propiedad Intelectual relacionados con el Comercio (ADPIC). El ADPIC es el acuerdo internacional más importante ratificado por España (1994) en materia de protección de bienes inmateriales. Su art. 39.2 protege la "información no divulgada", siempre que sea secreta, tenga un valor comercial por ello y haya sido objeto de medidas razonables de protección por la persona que legítimamente la controla. Sobre esta cuestión, véase PORTELLANO DíEZ, P., "Protección de la información no divulgada", en IGLESIAS PRADA, J.L. (coord.), Los derechos de propiedad intelectual en la Organización Mundial del Comercio: el Acuerdo sobre Aspectos de los Derechos de Propiedad Intelectual relacionados con el Comercio, Centro de Estudios para el fomento de la Investigación, 1997, págs. 335 y ss.

${ }^{18}$ Según Gómez SeGADE, J.A., El secreto industrial..., op.cit., pág. 50, “(...) esta diversidad de nombres sólo consigue enturbiar el concepto del secreto empresarial y crear una situación de inseguridad jurídica".

${ }^{19}$ El legislador ha configurado un concepto amplio de secreto empresarial. El Considerando 14 de la Directiva 2016/943 reconoce que "(...) es importante formular una definición homogénea del término (...), sin restringir el objeto de la protección contra la apropiación indebida. Dicha definición debe construirse pues de forma que incluya los conocimientos técnicos, la información 
construye sobre estos tres requisitos, que coinciden con los que había establecido previamente la doctrina ${ }^{20}$.

Los secretos empresariales responden a costosos y largos procesos de desarrollo que justifican su protección ${ }^{21}$. No obstante, para que la información en cuestión pueda ser tutelada, deben concurrir los siguientes requisitos.

a) Información secreta

La información debe ser secreta, es decir, no ser conocida por el público ni formar parte del denominado "estado de la ciencia". El art. 1.1.a) de la Ley 1/2019 define el término "secreto" desde una perspectiva subjetiva, pues exige que no sea conocida ni fácilmente accesible por las personas pertenecientes a los círculos en que normalmente se utilice ese tipo de información.

Es el presupuesto capital del régimen de tutela del secreto empresarial. Otorgar protección a información pública no solo es injustificable, sino también antieconómico. Por ello, la jurisprudencia rechaza la aplicación de esta excepción a información que ha sido previamente publicada ${ }^{22}$.

b) Valor empresarial

La información debe tener valor empresarial, tanto de carácter real o potencial, como consecuencia de su carácter secreto (art. 1.1.b de la Ley 1/2019).

El término "valor" ha sido tradicionalmente definido por la doctrina de manera subjetiva $^{23}$. No es necesario que la información sea objetivamente relevante en términos competitivos; basta que de ella se derive un valor añadido para su

empresarial y la información tecnológica, siempre que exista un interés legítimo por mantenerlos confidenciales y una expectativa legítima de que se preserve dicha confidencialidad".

20 Gómez SeGAdE, J.A., El secreto industrial..., op.cit., pág. 187; y, SUÑOL LUCEA, A., El secreto empresarial..., op.cit., pág. 105.

${ }^{21}$ Como pone de relieve el Considerando 4 de la Directiva 2016/943, existe un importante riesgo en torno a la utilización ilícita de información confidencial de las empresas.

${ }^{22}$ STGUE de 13 de enero de 2017, asunto T-189/14.

${ }^{23}$ CARBAjo CAScón, F., "Violación de secretos...", op.cit., pág. 1538. 
titular. Esa información debe ser la base de una ventaja competitiva ${ }^{24}$ que permita a su titular posicionarse en una mejor situación que sus competidores ${ }^{25}$. El término "empresarial" limita el contenido de la información al círculo de actividad de la empresa ${ }^{26}$. La jurisprudencia define la empresa como el conjunto de recursos y capacidades organizadas que ejercen una actividad económica para el mercado, con independencia de su forma jurídica ${ }^{27}$.

Dentro del concepto de información empresarial se engloba información de distinta naturaleza, siendo común la distinción entre secreto comercial e industrial:

- El secreto comercial está relacionado con cuestiones organizativas, financieras y de marketing, como la selección de productos; los análisis de mercados y de la competencia; las estrategias de marketing; las cifras de ventas; los resultados empresariales; la información relativa al nivel de homogeneización, estructuración y formalización empresarial; los análisis de unidades de negocios estratégicos; los proyectos financieros; o las fuentes de financiación, entre muchos otros ${ }^{28}$.

- El secreto industrial está relacionado con información técnicocientífica, como la composición de los productos; los planes de ejecución de los proyectos; las propuestas y proyectos de procesos

\footnotetext{
${ }^{24}$ Como señala PORTER, M.E., La ventaja competitiva de las naciones, Plaza \& Janés, 1991, la ventaja competitiva hace referencia a una característica o circunstancia de la empresa que le permite posicionarse en una mejor situación que sus competidores. Desde esta óptica, el secreto empresarial puede mejorar el nivel de eficiencia del mercado, al ser un mecanismo de expulsión de las empresas menos competitivas. La empresa explotadora del secreto puede experimentar beneficios que inciten a las competidoras a mejorar su desempeño. Así, se ven forzadas a afrontar costes de desarrollo, que pueden suponer la expulsión de aquellas empresas que bien no tengan capacidad económico-financiera suficiente para afrontarlos bien no realicen los ajustes estratégicos convenientes.
}

${ }^{25}$ SUÑOL LUCEA, A., El secreto empresarial..., op.cit., pág. 146.

${ }^{26}$ Siguiendo a Gómez SEGADE, J.A., El secreto industrial..., op.cit., pág. 47, el calificativo de "secreto empresarial" obedece a que la nota común de toda esa información de naturaleza variada es la empresa.

${ }^{27}$ SSTJUE de 17 de febrero de 1993 (asuntos acumulados C-159/91 y C-160/91); y, de 23 de abril de 1993 (asunto C-41/90).

${ }^{28}$ Gómez SeGADE, J.A., El secreto industrial..., op.cit., pág. 57. 
productivos; y, las fórmulas o los análisis de sustancias, entre muchos otros $^{29}$.

Esta distinción entre secretos comerciales e industriales es útil a efectos dogmáticos. Sin embargo, en la práctica, lo relevante es que concurran los requisitos del art. 1 de la Ley 1/2019. Por ello, dicho precepto incluye en el concepto empresarial a la información de naturaleza tecnológica, científica, industrial, comercial, organizativa y financiera ${ }^{30}$.

Se excluye del secreto empresarial el denominado "skill and knowledge". Dicho concepto alude a las capacidades, habilidades y conocimientos genéricos desarrollados por los trabajadores en el desempeño de sus puestos de trabajo en la empresa ${ }^{31}$. Estos conocimientos pueden ser utilizados por los trabajadores en otras empresas, una vez ha finalizado la relación laboral ${ }^{32}$, no así la información secreta que hubieran conocido por razón de su puesto de trabajo ${ }^{33}$.

\section{c) Adopción de medidas razonables de protección}

Por último, el titular del secreto empresarial debe establecer medidas de protección que evidencien su voluntad de mantener el secreto ${ }^{34}$.

\footnotetext{
${ }^{29}$ Gómez Segade, J.A., El secreto industrial..., op.cit., pág. 90.

30 Como afirma MASSAGUER FuENTES, J., "De nuevo sobre la protección jurídica de los secretos empresariales: a propósito de la Ley 1/2019, de 20 de febrero, de Secretos Empresariales", Actualidad Jurídica Uría Menéndez, no 51, 2019, pág. 52, "la definición de secreto empresarial supera definitivamente, en cuanto a su tratamiento legal se refiere, la tradicional diferencia entre secretos industriales y comerciales, que queda reservada al ámbito de la explicación descriptiva".

${ }^{31}$ Esta distinción, recogida por SUÑOL LUCEA, A., El secreto empresarial..., op.cit., pág. 260, se contempla también en la Exposición de Motivos de la Ley 1/2019.
}

${ }^{32}$ SAP Barcelona de 26 de octubre de 2005.

${ }^{33} \mathrm{~A}$ pesar de que en la actualidad el deber de secreto no se establece expresamente en la legislación laboral (antes sí la contemplaba el art. 72 de la derogada Ley del Contrato de Trabajo de 1944), Montoya Melgar, A., Derecho del trabajo, Tecnos, 1994, pág. 320, afirma que "no debe concluirse precipitadamente que tan importante obligación haya desaparecido, pues de la propia naturaleza de las cosas se desprende su pervivencia como aspecto imprescindible del deber de buena fe". En el ámbito de la función pública, el art. 53.12 del Real Decreto Legislativo $5 / 2015$, de 30 de octubre, por el que se aprueba el texto refundido de la Ley del Estatuto Básico del Empleado Público, impone dicho deber de secreto.

${ }^{34}$ En palabras de MASSAGUER FUENTES, J., "De nuevo sobre la protección...”, op.cit., pág. 57, "la satisfacción de esta condición exige, por una parte, que el titular de la información o conocimiento secretos disponga medidas que, por su naturaleza, sean apropiadas para mantener su reserva (...) y, por otra parte, que las medidas dispuestas sean, por su configuración e implementación y a la luz de las circunstancias del caso, razonablemente suficientes para ello". 
El titular es cualquier persona, física o jurídica, que ejerza el control sobre la información secreta (art. 1.2 de la Ley 1/2019). Definir al titular mediante el concepto de control ${ }^{35}$ permite que, en caso de transmisión o cesión de la información mediante licencia (arts. 4 y ss. de la Ley 1/2019, de Secretos Empresariales), el licenciatario también pueda ejercer las acciones de defensa previstas en la ley.

Las medidas de protección deben ser razonables, de forma que la voluntad de conservar el secreto sea reconocible, por ejemplo, mediante la imposición contractual de una obligación de secreto ${ }^{36}$. Esta exigencia es lógica, pues no debería impedirse el uso y divulgación de información que ni siquiera el titular ha manifestado querer proteger (doctrina de los actos propios ${ }^{37}$ ).

Como hemos dicho, las empresas se ven obligadas a suministrar mucha información "sensible" a la Administración (por ejemplo, art. 5 TRLPCIC) ) $^{38}$ No obstante, la normativa ambiental reconoce a los titulares de las instalaciones y de los productos objeto de autorización la posibilidad de que determinen la información que, a su juicio, es confidencial (entre otros, arts. 12.1 TRLPCIC, 15.2 LEA y 7 del Reglamento para la ejecución de la Ley Básica de Residuos Tóxicos y Peligrosos). Reconocimiento que ha recogido también la normativa autonómica en la materia ${ }^{39}$.

\footnotetext{
${ }^{35}$ Según MASSAGUER FUENTES, J., "De nuevo sobre la protección...", op.cit., pág. 64, se entiende por control el "sometimiento al poder de disposición y dominio fáctico de una persona", tanto si se adquiere originaria (descubrimiento o creación) como derivadamente (cesión).

${ }^{36}$ CARBajo CAscón, F., "Violación de secretos...", op.cit., pág. 1533; y, MASSAGUER FuenTES, J., "De nuevo sobre la protección...", op.cit., pág. 58.

${ }^{37}$ Sobre la doctrina de los actos propios puede verse la excepcional obra de DíEZ PICAZO, L., La doctrina de los actos propios: un estudio crítico sobre la jurisprudencia del Tribunal Supremo, Civitas, Cizur Menor, 2014.

38 Sobre los datos confidenciales como límite a la información pública en el ámbito del control integrado de la contaminación, véase REVUeLTA PÉREZ, I., El control integrado de la contaminación en el Derecho Español, Marcial Pons, 2003, págs. 221 a 226.

39 Contemplan esta posibilidad, en términos similares, la Ley aragonesa de Prevención y Protección Ambiental (art. 10.2); la Ley de Protección Ambiental Integrada de la Región de Murcia (arts. 13 y 31.1.e); la Ley valenciana de Prevención, Calidad y Control Ambiental de Actividades (arts. 27.1.g y 53.2.1.g); la Ley catalana de Prevención y Control Ambiental de las Actividades (art. 17.1.g); la Ley de Evaluación Ambiental de las Islas Baleares (art. 5); la Ley de Protección Ambiental de Castilla y León (art. 27.2.b); y la Ley Foral de Intervención para la Protección Ambiental (arts. 20.2.c y 26.b).
} 
La calificación del titular no vincula a la Administración ${ }^{40}$. Sin embargo, esta declaración del titular es, a todas luces, un ejemplo de medida razonable de protección del secreto.

EI TJUE se ha pronunciado sobre la posibilidad de considerar como confidencial información que inicialmente no ha sido calificada como tal por su titular ${ }^{41}$. El Tribunal estableció que el titular de la información podía oponer el carácter confidencial de la información a una solicitud de acceso, a pesar de que inicialmente no hubiera calificado la información como reservada. La argumentación del Tribunal se basa en que la Directiva 2003/4 impone el examen de la solicitud, con independencia de que la petición de tratamiento confidencial sea anterior o posterior a la solicitud de acceso.

Entendemos que no puede excluirse automáticamente el calificativo de secreto empresarial por no haber solicitado inicialmente el tratamiento confidencial de la información. La petición de confidencialidad es una de las medidas razonables de protección de que dispone el titular, pero no la única. De hecho, la oposición del titular a la solicitud de acceso de un tercero es también una medida de protección razonable en los términos del art. 1 de la Ley 1/2019. Supuesto distinto sería aquel en el que el titular ni solicita inicialmente el tratamiento confidencial ni se opone a una solicitud de acceso. Puesto que, en ese caso, la información no podría protegerse por el régimen del secreto empresarial, al faltar uno de sus requisitos básicos.

\footnotetext{
${ }^{40}$ FeRnándeZ Ramos, S., El derecho de acceso a los documentos..., op.cit, pág. 525, niega que las peticiones de las empresas vinculen a la Administración. Sobre la información facilitada por terceros de forma voluntaria (excepción del art. 13.2.g) de la Ley 27/2006), RAZQUIN LIZARRAGA, M.M., La confidencialidad de los datos..., op.cit., pág. 334, enfatiza la necesidad de interpretar restrictivamente el concepto de "entrega voluntaria", como aquella que se realiza sin que exista obligación alguna de realizarla. Se excluyen así los documentos entregados de forma obligatoria y como carga jurídica.

${ }^{41}$ La STJUE de 23 de noviembre de 2016 (asunto C-442/14) resolvió la cuestión en los siguientes términos: "la circunstancia de que el solicitante de una autorización de comercialización de un producto fitosanitario o biocida no solicitara, durante el procedimiento previsto para la obtención de esta autorización, el tratamiento confidencial de la información presentada en el marco de este procedimiento (...), no obsta para que la autoridad competente, ante la que un tercero ha presentado, tras la finalización de dicho procedimiento, una solicitud de acceso a esta información sobre la base de la Directiva 2003/4, examine la oposición de dicho solicitante a esta solicitud de acceso y, en su caso, deniegue ésta en aplicación del artículo 4, apartado 2, párrafo primero, letra d), de esta Directiva basándose en que la divulgación de dicha información afectaría negativamente a la confidencialidad de la información comercial o industrial".
} 


\title{
3. Distinción con los derechos de propiedad industrial
}

La Ley 27/2006 distingue los secretos comerciales e industrial (art. 13.2.d) y los derechos de propiedad industrial (art. 13.2.e) como diferentes excepciones al derecho de acceso. Se trata de diferentes instrumentos de protección de bienes inmateriales ${ }^{42}$, tanto por su intensidad como por la naturaleza del objeto protegido ${ }^{43}$.

En primer lugar, los derechos de propiedad industrial (patentes ${ }^{44}$, modelos de utilidad $^{45}$, topografías de productos semiconductores ${ }^{46}$ y obtenciones vegetales ${ }^{47}$ ) reconocen un mayor nivel de protección, pues conceden a su titular

\begin{abstract}
42 MASSAguer FuenteS, J., "Aproximación sistemática general al Derecho de la competencia y de los bienes inmateriales", Revista general de derecho, № 544-545, 1990, págs. 245 a 263.

${ }^{43}$ FeRnÁndez RAmOs, S., El derecho de acceso a los documentos..., op.cit, pág. 519, afirma "la finalidad última de la legislación en materia de patentes es la de impulsar la innovación tecnológica de un país, imprescindible para elevar el nivel de competitividad de su industria en su conjunto, mientras que el secreto industrial y comercial tiene por objeto la protección de la competitividad de las empresas individualmente consideradas". Si bien, CARBAJO CAScón, F., "Violación de secretos...", op.cit., pág. 1539, apunta que ambos mecanismos de tutela protegen "los resultados del esfuerzo creativo para estimular la creación y la inversión en el plano económico industrial y comercial, y, con ello, fomentar la libre competencia y el desarrollo económico"
\end{abstract}

${ }^{44}$ La patente es un derecho sobre una invención que permite a su titular prohibir la utilización y venta durante 20 años. Los requisitos de patentabilidad son: (1) que se trate de una invención nueva a nivel mundial, denominada novedad absoluta; (2) que sea fruto de una actividad inventiva no fácilmente deducible del estado de la ciencia; y, (3) que posea una aplicación industrial (arts. 6, 8 y 9 de la Ley 24/2015, de 24 de julio, de Patentes). Sobre el derecho de patentes puede verse, entre otros, FERNÁNDEZ DE CórDOBA, S., Derecho de patentes e investigación científica, Tirant lo Blanch, 1996.

45 El modelo de utilidad protege invenciones de menor grado que, a pesar de su novedad, se caracterizan por una configuración o estructura ventajosa desde una perspectiva práctica. Mediante este sistema se pretende proteger precisamente esa invención práctica, relacionada con su forma y función (art. 137 de la Ley 24/2015, de 24 de julio, de Patentes). Sobre el modelo de utilidad puede verse, entre otros, VAREA SANZ, M., El modelo de utilidad: Régimen jurídico, Aranzadi, 1996.

${ }^{46}$ Los materiales semiconductores son sustancias químicas que se comportan como conductor o aislante según factores externos como el campo eléctrico o magnético, la presión, la radiación que incide en ellos o la temperatura del ambiente (art. 1 de la Ley 11/1988, de 3 de mayo, de Protección Jurídica de las Topografías de los Productos Semiconductores.). Es decir, se trata de sustancias que permitirán o no el paso de electricidad en función de las circunstancias externas. Lo que se protege mediante este mecanismo son las configuraciones tridimensionales 0 esquemas del trazado de piezas de un chip o circuito integrado (art. 2 de la Ley 11/1988, de 3 de mayo, de Protección Jurídica de las Topografías de los Productos Semiconductores).

47 Las obtenciones vegetales protegen el derecho del obtentor de una nueva variedad vegetal, que posee caracteres propios y diferenciables (arts. 5 a 9 de la Ley/2000, de 7 de enero, de Régimen Jurídico de Protección de las Obtenciones Vegetales). Sobre las obtenciones vegetales puede verse, entre otros, GARCíA VIDAL, Á., "El contenido del derecho de "obtentor» de una variedad vegetal (luces y sombras del Convenio de la UPOV)", Revista de Derecho Mercantil, no 279, 2011, pág. 99 y ss. 
un derecho de utilización exclusiva y excluyente oponible erga omnes (ius prohibendi), aunque de carácter temporal ${ }^{48}$.

El secreto empresarial, por su parte, se protege a través de la Ley 1/2019 y reconoce a su titular el resarcimiento económico ante la divulgación, utilización y revelación ilícita del secreto. No se otorga, pues, un derecho subjetivo oponible erga omnes propiamente dicho ${ }^{49}$.

De hecho, según las circunstancias concurrentes, los regímenes de protección del secreto empresarial y de los derechos de propiedad industrial podrán ser excluyentes ${ }^{50}$ o compatibles ${ }^{51}$.

En segundo lugar, existen importantes diferencias en cuanto al objeto protegible. Pese a que determinada información puede ser protegida mediante ambos sistemas (como ocurre, por ejemplo, con las invenciones) ${ }^{52}$; el ámbito de aplicación del secreto es mayor, puesto que incluye información no protegible por un derecho de propiedad industrial.

48 El art. 2 del Texto Refundido de la Ley de Propiedad Intelectual de 1996 reconoce "La propiedad intelectual está integrada por derechos de carácter personal y patrimonial, que atribuyen al autor la plena disposición y el derecho exclusivo a la explotación de la obra, sin más limitaciones que las establecidas en la Ley'. En similar sentido, arts. 59, 60 y 148 de la Ley 24/2015, de 24 de julio, de Patentes; art. 12 de la Ley 3/2000, de 7 de enero, de Régimen Jurídico de Protección de las Obtenciones Vegetales; y, art. 5 de la Ley 11/1988, de 3 de mayo, de Protección Jurídica de las Topografías de los Productos Semiconductores.

${ }^{49}$ La protección del secreto empresarial continúa enmarcándose en el ámbito del Derecho de la competencia, pues la propia Exposición de Motivos de la Ley 1/2019 reconoce "(...) la atribución del carácter de competencia desleal a la violación de secretos empresariales".

50 Son mecanismos de tutela excluyentes siempre que la normativa imponga la publicación de la información tal y como ocurre en el derecho de patentes (art. 41 de la Ley 24/2015, de 24 de julio, de Patentes). Se imposibilita así considerar la información como secreta.

51 Según MASSAGUER FUENTES, J., "De nuevo sobre la protección...", op.cit., pág. 54, se admite la compatibilidad entre ambos sistemas de protección respecto al contenido secreto de las topografías (art. 4.2 de la Ley 11/1988, de 3 de mayo, de Protección Jurídica de las Topografías de los Productos Semiconductores) y los conocimientos sobre la explotación de las invenciones patentadas que ni se contienen explícitamente ni pueden deducirse con facilidad de la descripción de la patente (art. 84 de la Ley 24/2015, de 24 de julio, de Patentes).

${ }^{52}$ Siguiendo a MASSAGUER FUENTES, J., "De nuevo sobre la protección...", op.cit., pág. 54, cada empresa debe decidir de qué forma desea proteger sus invenciones. Mediante el secreto empresarial no se publica la información, pero no puede impedirse que otros competidores la desarrollen mediante métodos legítimos (definidos en el art. 2.1 de la Ley 1/2019). Por otro lado, la concesión de un derecho de propiedad industrial supone la publicación y la integración de esa información en el estado de la ciencia, reconociendo a su titular un derecho de contenido negativo (ius prohibendi). 
El secreto puede proteger información de naturaleza muy diversa, de naturaleza no técnico-científica (como, por ejemplo, comercial, financiera u organizativa) y que no podría determinar la concesión de un derecho de propiedad industrial. Lo mismo ocurre con los descubrimientos, que por referirse a un suceso, circunstancia o cosa existente pero desconocida hasta el momento, no puede tutelarse mediante los derechos de propiedad industrial, pues estos exigen, en mayor o menor medida, que el bien protegido sea novedoso ${ }^{53}$.

Se evidencia que el secreto empresarial es un mecanismo de tutela distinto de los derechos de propiedad industrial.

\section{LA DENEGACIÓN DEL ACCESO COMO MECANISMO DE TUTELA: PRESUPUESTOS}

Una vez delimitado el concepto de secreto empresarial, procede desarrollar los presupuestos para que la Administración pueda denegar la solicitud de acceso amparándose en esta excepción.

La denegación de la información solicitada es una importante garantía del secreto empresarial. El art. 13.2.d) de la Ley 27/2006 exige la concurrencia de los siguientes presupuestos: 1) la finalidad de proteger intereses económicos legítimos; 2) el reconocimiento legal de la confidencialidad; y 3) la divulgación es perjudicial para el secreto y su titular ${ }^{54}$.

El Anexo de la Orden AAA/1601/2012, de 26 de junio, por la que se dictan instrucciones en torno a la aplicación de la Ley 27/2006, ilustra los requisitos exigidos con el siguiente ejemplo: "en los casos de proyectos de obras, la divulgación de aquellos elementos de la documentación remitida por el licitador no podrá incluir lo que el propio licitador haya declarado confidencial, con especial consideración a los secretos técnicos, comerciales y demás aspectos confidenciales, conforme a lo previsto en el Real Decreto Legislativo 3/2011, de 14 de noviembre, por el que se aprueba el Texto Refundido de la Ley de

\footnotetext{
53 Gómez SeGADE, J.A., El secreto industrial..., op.cit., pág. 97.

${ }^{54}$ El art. 13.2.d) de la Ley 27/2006 establece: "Las solicitudes de información ambiental podrán denegarse si la revelación de la información solicitada puede afectar negativamente [...] a la confidencialidad de datos de carácter comercial e industrial, cuando dicha confidencialidad esté prevista en una norma con rango de Ley o en la normativa comunitaria, a fin de proteger intereses económicos legítimos"
} 
Contratos del Sector Público. Por el contrario, no afecta [...] el suministro de información relativa a un proyecto técnico que forma parte de un expediente ya divulgado mediante la preceptiva fase de información pública".

La decisión de la Administración debe ser idónea para el fin perseguido, necesaria y proporcional ${ }^{55}$. En cualquier caso, debe ser una resolución motivada (art. 10.2.c de la Ley $27 / 2006)^{56}$, que posibilite, en su caso, el ejercicio de las correspondientes acciones judiciales (art. 20 de la Ley 27/2006).

\section{La protección de intereses económicos legítimos}

El primer requisito exige que la información solicitada se refiera a datos comerciales e industriales cuya protección se justifique por "intereses económicos legítimos".

EI TJUE ha reconocido desde antiguo el legítimo interés de las empresas de proteger sus secretos comerciales. El principio de protección de los secretos comerciales es un principio general del Derecho de la Unión Europea, vinculado al derecho de propiedad y la libertad de empresa. De hecho, el Tribunal ha establecido la conveniencia de negar el acceso a empresas competidoras, pues "cualquier otra solución llevaría al inadmisible resultado de que una empresa pudiera verse tentada a plantear una reclamación ante la Comisión únicamente con vistas a tener acceso a los secretos comerciales de los competidores" ${ }^{\prime \prime}$.

\footnotetext{
${ }^{55}$ La denegación es una medida idónea para proteger los secretos empresariales. Será también una medida necesaria cuando no existan otros medios alternativos menos lesivos. No puede considerarse una medida proporcional si la información es irrelevante. En cumplimiento de estas exigencias, deberá preferirse la difusión parcial (art. 14 de la Ley 27/2006) frente a la denegación cuando aquélla satisfaga igualmente la protección del secreto. Como afirma CASADO CASADO, L., "El acceso a la información ambiental en España: luces...", op.cit., pág. 258, "La concurrencia de alguna de las circunstancias establecidas en el artículo 13 tampoco implica necesariamente la denegación de la totalidad de la información solicitada, ya que la ley 27/2006, en el artículo 14, impone a la autoridad pública la obligación de suministro parcial de la información solicitada cuando la información exenta de divulgación pueda disociarse del resto de información no amparada por la excepción".

${ }^{56}$ Como pone de manifiesto, RAZQUIN LIZARRAGA, J.A, "El acceso a la información en materia de medio ambiente en España: balance y retos de futuro", Revista Catalana de Dret Ambiental, vol. 9, no 1, 2018, pág. 33, la motivación "ha de ser específica sin que sirvan modelos estereotipados, expresar las normas que amparan el bien o interés legítimo protegido y reflejar la ponderación de los intereses en conflicto llevada a cabo".

57 STJCE de 24 de junio de 1986 (asunto C-53/85). Puede verse también, entre muchas otras, las SSTJUE de 19 de mayo de 1994 (asunto C-36/92), de 14 de febrero de 2008 (asunto C450/06), y de 29 de marzo de 2012 (asunto C-1/11); que reconocen los secretos comerciales como límite al suministro de información por la Administración.
} 
Los secretos comerciales constituyen un interés económico merecedor de tutela, pues es legítimo que las empresas quieran proteger aquella información relevante sobre su actividad empresarial. El primer paso para denegar una solicitud de acceso es analizar la concurrencia de los requisitos del art. 1.1 de la Ley $1 / 2019$.

\section{Reconocimiento legal de la confidencialidad}

Para poder denegar la solicitud de acceso, es necesario que una norma legal o comunitaria reconozca el carácter secreto, reservado o confidencial de la información en cuestión (o de parte de ella).

Como ha establecido el TJUE ${ }^{58}$, dicho reconocimiento debe realizarse de forma clara y exacta59; a fin de evitar la arbitrariedad de la Administración. Es aconsejable que sea la normativa sectorial la que reconozca la confidencialidad de la información junto a la ordenación de los procedimientos de que se trate, y no que se establezca un reconocimiento genérico e impreciso ${ }^{60}$. En ningún caso 58 La STJUE de 14 de febrero de 2012 (asunto C-204/09) resuelve una cuestión prejudicial
planteada acerca de "la confidencialidad de los procedimientos de las autoridades públicas"
como causa de denegación, prevista en el artículo 4.1.a) de la Directiva 2003/4. Aunque la
Sentencia no aborda la excepción del secreto empresarial; las conclusiones del Tribunal son
útiles a nuestros efectos. La cuestión se centraba en determinar si un reconocimiento genérico
de confidencialidad cumplía la exigencia de que la confidencialidad de los procedimientos
estuviera dispuesta por la ley.

El Tribunal entendió que el requisito "(...) según el cual la confidencialidad de los procedimientos de las autoridades públicas debe estar dispuesto por la ley puede considerarse cumplido por la existencia, en el Derecho nacional del Estado miembro afectado, de una norma que establece, de manera general, que la confidencialidad de los procedimientos de las autoridades públicas constituye un motivo de denegación de acceso a la información medioambiental en poder de esas autoridades, siempre y cuando el Derecho nacional defina claramente el concepto de procedimiento, lo que corresponde verificar al juez nacional."

59 En la citada Sentencia de 14 de febrero de 2012 (asunto C-204/09), el Tribunal de Justicia sostiene que "el legislador de la Unión ha querido claramente que en el Derecho nacional exista una norma expresa cuyo alcance esté determinado con exactitud, (...) no procede que las autoridades públicas puedan determinar unilateralmente las circunstancias en que puede oponerse la confidencialidad contemplada en el artículo 4, apartado 2, de la Directiva 2003/4, lo que implica, en particular, que el Derecho nacional debe definir claramente el alcance del concepto de «procedimientos» de las autoridades públicas contemplado en esta disposición, que remite a las etapas finales de los procesos de toma de decisiones por las autoridades públicas".

60 Las Conclusiones de la Abogado General Sharpston (asunto C-204/09) enfatizan que la confidencialidad se reconozca de forma clara para evitar la arbitrariedad administrativa. En particular, que se reconozca "de un modo independiente respecto del motivo de denegación de una solicitud de información". Este último inciso es consecuencia de que, en la cuestión planteada, la ley alemana de trasposición de la Directiva 2003/4 integraba en un mismo texto tanto la causa de denegación basada en la confidencialidad de los procedimientos administrativos como un reconocimiento general de confidencialidad de dichos procedimientos. 
la denegación podrá basarse en un reconocimiento contractual de la confidencialidad $^{61}$.

Diversas leyes ambientales reconocen la confidencialidad de información sensible para la empresa. El art. 16 TRLPCIC permite excluir documentos sensibles del trámite de audiencia pública. Y, en términos similares, el art. 26.5 de la Ley de Residuos y Suelos Contaminados reconoce que la información suministrada a efectos de trasladar residuos del territorio nacional gozará de confidencialidad.

En el mismo sentido, el art. 15.1 LEA establece la necesidad de que las autoridades respeten la información confidencial aportada por el promotor. También la normativa autonómica dictada en la materia recoge este reconocimiento ${ }^{62}$.

Lo mismo ocurre en el Derecho de la Unión Europea. El art. 118.2 del Reglamento REACH reconoce la confidencialidad de la información sobre la composición completa de un preparado; el uso, función o aplicación exactos de un preparado; el tonelaje exacto del preparado; y, las relaciones entre el fabricante y sus distribuidores ${ }^{63}$. En consecuencia, la ECHA (Agencia Europea de Sustancias y Preparados Químicos) está facultada para ponderar las circunstancias en juego y, en su caso, denegar el acceso a información que afecte a intereses comerciales legítimos.

\footnotetext{
61 La SAN de 30 de junio de 2016 niega la posibilidad de que la confidencialidad exigida se encuentre prevista en un contrato. En palabras de la Audiencia Nacional "(...) la Ley 27/2006 y la Directiva 2003/4 exigen que la confidencialidad esté prevista en una norma con rango de ley, (...) en este caso, no puede constatarse que tal requisito se cumpla, pues no se expresa en el acuerdo combatido la existencia de la norma con rango de Ley que legitime la previsión de confidencialidad".

62 Todas las normas ambientales establecen, con mayor o menor fortuna, dicha confidencialidad: la Ley valenciana de Prevención, Calidad y Control Ambiental de Actividades (arts. 55 y 30); la Ley andaluza de Gestión Integral de la Calidad Ambiental (art. 4); la Ley catalana de Prevención y Control Ambiental de las Actividades (arts. 20 y 41); la Ley aragonesa de Prevención y Protección Ambiental (art. 55); la Ley de Evaluación Ambiental de Castilla-La Mancha (art. 19); la Ley extremeña de Protección Ambiental (art. 13); y, la Ley de Protección del Medio Ambiente de La Rioja (art. 21.b). En particular, resulta ilustrativa la claridad del art. 24.1, párrafo segundo, de la Ley gallega de Protección Ambiental: "No obstante, en casos justificados, debidamente motivados, y de acuerdo con el derecho comunitario y demás legislación vigente, podrán establecerse restricciones a dicha transparencia informativa por razones de defensa, confidencialidad de la información, secreto industrial, respeto de la intimidad u otra análoga".
}

${ }^{63}$ STGUE de 13 de enero de 2017 (asunto T-189/14). 
Los arts. 11, 13, 36 y 38 del Reglamento (CE) № 726/2004, del Parlamento Europeo y del Consejo, de 31 de marzo de 2004, por el que se establecen procedimientos comunitarios para la autorización y el control de los medicamentos de uso humano y veterinario y por el que se crea la Agencia Europea de Medicamentos, reconocen la confidencialidad de determinada información que mantendrá su carácter reservado cuando así los exijan las circunstancias concurrentes ${ }^{64}$.

Tanto el legislador nacional como el de la Unión se han preocupado por reconocer, de manera más o menos precisa, la confidencialidad de diferentes tipos de información sensible. No obstante, en ocasiones, el legislador ha negado la confidencialidad de la información ${ }^{65}$, lo que impone su divulgación.

EI TJUE ha insistido, como hemos expuesto, en la necesidad de configurar un principio general de confidencialidad y de clarificar la cuestión. La Ley 1/2019 supone un importante avance al positivizar una definición para un bien jurídico de contenido tan diverso y variable. Sin embargo, la aprobación de esta ley no debe interpretarse como un reconocimiento general de confidencialidad a toda información empresarial secreta. Su art. 2 pretende impedir precisamente que dicha norma se utilice como un reconocimiento genérico y absoluto de confidencialidad que pueda oponerse a, en cuanto a nosotros nos importa, las obligaciones ambientales ${ }^{66}$. Ante una solicitud de acceso a información empresarial secreta es necesario analizar los hechos concurrentes en cada supuesto y ponderar los intereses en juego ${ }^{67}$.

\footnotetext{
${ }^{64}$ La STJUE de 5 de febrero de 2018 (asunto T-235/15) niega la existencia de una presunción general de confidencialidad en el Reglamento no 726/2004.

65 STJUE de 16 de diciembre de 2010 (asunto C-266/09). Un ejemplo, que de hecho se analiza en la Sentencia, es el art. 14, párrafo segundo, de la derogada Directiva 91/414.

${ }^{66}$ El último párrafo del art. 2.3 de la Ley 1/2019 establece que "[...] no podrá invocarse la protección dispensada por esta ley para obstaculizar la aplicación de la normativa que exija a los titulares de secretos empresariales divulgar información o comunicarla a las autoridades administrativas o judiciales en el ejercicio de las funciones de éstas, ni para impedir la aplicación de la normativa que prevea la revelación por las autoridades públicas europeas o españolas, en virtud de las obligaciones o prerrogativas que les hayan sido conferidas por el Derecho europeo o español, de la información presentada por las empresas que obre en poder de dichas autoridades".

${ }^{67}$ Como afirmó SAINZ MORENO, F., "Secreto e información...", op.cit., pág. 2981, la relación entre publicidad y secreto precisa de una ponderación entre los intereses públicos y privados concurrentes.
} 


\section{Divulgación perjudicial: Ponderación de los intereses en conflicto}

Por último, la divulgación podrá denegarse siempre que afecte negativamente al secreto empresarial. Para ello será necesario ponderar los intereses en conflicto68. La Directiva 2003/4 también prevé esta exigencia en su artículo 4, segundo párrafo, cuyo contenido conviene reproducir: "Los motivos de denegación mencionados en los apartados 1 y 2 deberán interpretarse de manera restrictiva teniendo en cuenta para cada caso concreto el interés público atendido por la divulgación. En cada caso concreto, el interés público atendido por la divulgación deberá ponderarse con el interés atendido por la denegación de la divulgación".

Este requisito, tal y como lo ha entendido el TJUE en su Sentencia de 28 de julio de 2011 (asunto C-71/10), impone dos actividades distintas ${ }^{69}$.

En primer lugar, la Administración debe determinar si la divulgación afecta negativamente al secreto empresarial. La jurisprudencia ha establecido que se produce una afectación negativa cuando la información publicada es de carácter sensible y se refiere a estrategias comerciales de la empresa o contiene datos técnicos relevantes ${ }^{70}$. La divulgación de datos meramente descriptivos no constituye un perjuicio efectivo para la empresa ${ }^{71}$. Ni siquiera cuando hubieran sido compilados por la empresa, salvo que dichos datos revelasen conclusiones técnicas nuevas que pudieran proporcionar una ventaja competitiva ${ }^{72}$.

\footnotetext{
68 RAZQUin LiZARRAGA, M.M., La confidencialidad de los datos..., op.cit., pág. 337.

${ }^{69}$ La STJUE de 28 de julio de 2011 (asunto C-71/10) entendió que el segundo párrafo del art. 4 de la Directiva 2003/4 tiene una "función propia" respecto del primero, de manera que no se trata de una mera reiteración, distinguiéndose así dos actividades de ponderación distintas. La Sentencia afirma: "(...) dicha frase tiene una función propia, independiente de la primera frase del mismo párrafo. En efecto, la primera frase formula la obligación de ponderar cada uno de los motivos de denegación con el interés que presenta para el público la divulgación de la información. Si el único objeto de la segunda frase mencionada fuera la imposición de dicha obligación, ello no sería más que una repetición redundante y superflua del sentido de la primera frase del mismo párrafo".

70 STJUE de 9 de septiembre de 2014 (asunto T-516/11).

${ }^{71}$ STGUE de 13 de enero de 2017 (asunto T-189/14).

72 STJUE de 5 de febrero de 2018 (asunto T-235/15).
} 
El titular es quien debe justificar que la información es un secreto empresarial y que la divulgación es perjudicial ${ }^{73}$. Para ello, debe describir de forma concreta la importancia y utilidad de la información; así como los perjuicios reales derivados de la divulgación. No es posible justificar la denegación amparándose en perjuicios meramente hipotéticos ${ }^{74}$.

La primera tarea del órgano administrativo es analizar si, atendiendo a las circunstancias concurrentes, la divulgación tiene un impacto negativo sobre el secreto empresarial. La Administración debe partir de una interpretación restrictiva de las excepciones al derecho de acceso, tal y como exige el propio tenor literal del precepto ${ }^{75}$ y la consolidada jurisprudencia del TJUE que lo ha aplicado $^{76}$.

En segundo lugar, es necesario ponderar los intereses en conflicto en cada caso, esto es, el interés público atendido por la divulgación y el interés privado salvaguardado por la denegación 77 . En palabras de ARROYO JIMÉNEZ "La ponderación es [...] el tipo de discurso jurídico a través del cual se resuelven las colisiones entre principios, y consiste en identificar las circunstancias que deben concurrir para que un principio preceda a otros y fundamentar por qué en esas circunstancias es ese principio el de mayor peso"78.

\footnotetext{
${ }^{73}$ En caso de que no se acredite el impacto negativo sobre el secreto, se impone la divulgación (por todas, STS de 16 de octubre de 2017).

${ }^{74}$ STGUE de 13 de enero de 2017 (asunto T-189/14).

${ }^{75}$ Art. 13.4 de la Ley $27 / 2006$.

76 Entre muchas otras, SSTJCE de 17 de junio de 1998 (asunto C-321/96), de 12 de junio de 2003 (asunto C-316/01), y de 26 de junio de 2003 (asunto C-233/00); cuya doctrina ha sido acogida por los tribunales nacionales (por todas, STS de 17 de febrero de 2004 y 5 de abril de 2006; así como STSJ de Castilla-La Mancha de 26 de marzo de 2007, y STSJ de Castilla y León de 16 de abril de 2008).

77 Para SAINZ MoRenO, F., "Secreto e información...", op.cit., pág. 2972, "el interés privado al que aquí nos referimos (interés en defender la propia intimidad, la libertad, la seguridad, la actividad profesional o empresarial) no es sólo "privado" en el sentido de que sólo interese a los particulares singularmente considerados, sino que es también público en la medida en que lo son las libertades y los derechos fundamentales".

78 ARROYo JimÉnEZ, L., "Ponderación, proporcionalidad y Derecho Administrativo", en ORTEGA ÁlvareZ, L.I. y DE LA SiERRA Morón, S. (coords.), Ponderación y Derecho Administrativo, Marcial Pons, 2009, págs. 19 a 49.
} 
Como ha afirmado el TJUE, es posible que concurran cumulativamente más de un interés público y/o privado ${ }^{79}$. La divulgación puede obedecer a diferentes razones como "una mayor concienciación en materia de medio ambiente", "un intercambio libre de puntos de vista", "una más efectiva participación del público en la toma de decisiones medioambientales" y "la mejora del medio ambiente". Por otro lado, es posible que concurran varias de las excepciones del art. 13 de la Ley $27 / 2006$. El precepto, en suma, "tiene por objeto la ponderación de dos conceptos globales"80.

La Administración debe ponderar los intereses en juego atendiendo a las circunstancias concurrentes ${ }^{81}$. El legislador no puede configurar una ponderación genérica y previa $^{82}$, ni sustituir dicha ponderación del órgano administrativa por otra medida distinta. Únicamente puede establecer mediante ley criterios orientativos que faciliten la ponderación, siempre que con ello no impida a las autoridades realizar la debida apreciación comparada de los intereses en juego.

La ponderación puede verse influida por la existencia de presunciones legales, por lo que es necesario concretar sus efectos.

Por un lado, es posible que la legislación ambiental establezca una presunción legal en favor de la divulgación. Esto ocurre precisamente en el art. 13.5 de la Ley 27/2006, que impide ampararse en el secreto empresarial para denegar una

\footnotetext{
79 La STJUE de 28 de julio de 2011 (asunto C-71/10) afirma que "al ponderar los intereses públicos atendidos por la divulgación con los intereses atendidos por la denegación de la divulgación, con el fin de valorar una solicitud de que dicha información se ponga a disposición de una persona física o jurídica, puede tomarse en consideración acumulativamente varios motivos de denegación".

${ }^{80}$ STJUE de 28 de julio de 2011 (asunto C-71/10).

${ }^{81}$ La exigencia de ponderación explica que pueda divulgarse información a pesar de que afecte negativamente al secreto empresarial. En la jurisprudencia nacional puede verse las SSAN de 2 de julio de 2018 y de 19 de septiembre de 2019.

82 La STJUE de 16 de diciembre de 2010 (asunto C-266/09) afirmó que "(...) el artículo 4 de la Directiva 2003/4 debe interpretarse en el sentido de que la ponderación prescrita del interés público atendido por la divulgación de información medioambiental y del interés específico atendido por la denegación de la divulgación debe efectuarse en cada caso concreto sometido a las autoridades competentes, aun cuando el legislador nacional establezca mediante una disposición de carácter general criterios que permitan facilitar esa apreciación comparada de los intereses en juego".
} 
solicitud de información sobre emisiones en el medio ambiente ${ }^{83}$. La norma presume iuris et de iure la prevalencia del interés público atendido por la divulgación de información sobre emisiones en el medio ambiente.

Ante una solicitud de información sobre emisiones, la Administración no debe ponderar los intereses en conflicto; sino divulgar directamente la información ${ }^{84}$. Por ello, es sumamente importante concretar el concepto de "emisiones en el medio ambiente". EI TJUE lo ha definido como todo tipo de expulsión, vertido o liberación a la atmósfera, al agua o al suelo de sustancias, vibraciones, calor o ruido procedentes directa o indirectamente de la actividad humana ${ }^{85}$.

Por otro lado, la existencia de presunciones legales de confidencialidad plantea mayores problemas ${ }^{86}$. La legislación sectorial y el TJUE han reconocido presunciones generales de confidencialidad en diversos ámbitos ${ }^{87}$, con el fin de

${ }^{83}$ REVUELTA PÉREZ, I., El control integrado... op.cit., pág. 204, destaca la importancia del carácter público de la información sobre emisiones contaminantes de las empresas.

${ }^{84}$ SSTJUE de 23 de noviembre de 2016 (asuntos C-673/13 P y C-442/14).

${ }^{85}$ Las SSTJUE de 23 de noviembre de 2016 (asuntos C-673/13 P y C-442/14) exigen que las emisiones sean reales 0 , al menos, previsibles en términos de normalidad. No deben ser meramente hipotéticas. La información sobre emisiones incluye no sólo "las indicaciones relativas a la naturaleza, la composición, la cantidad, la fecha y el lugar de estas emisiones, sino también los datos relativos a las repercusiones a más o menos largo plazo de dichas emisiones en el medio ambiente" (C-442/14).

${ }^{86}$ La STJUE de 23 de noviembre de 2016 (asunto C-442/14) presume la confidencialidad del método de fabricación, la especificación de la impureza de la sustancia activa, los resultados de los lotes de producción de la sustancia activa, los métodos de análisis de las impurezas de la sustancia activa, las relaciones entre el productor/importador y el solicitante/titular de la autorización, la información sobre la composición completa de un producto fitosanitario y los nombres y direcciones de las personas que hayan participado en los ensayos en animales vertebrados (art. 63 del Reglamento (CE) no 1107/2009 del Parlamento Europeo y del Consejo, de 21 de octubre de 2009, relativo a la comercialización de productos fitosanitarios).

87 EI TJUE ha reconocido la existencia de presunciones generales de denegación de acceso a los documentos sobre controles de ayudas de Estado (STJUE de 29 de junio de 2010, asunto C139/07); a los documentos sobre controles de operaciones de concentración entre empresas (SSTJUE de 28 de junio de 2012, asuntos C-404/10 P y C-477/10 P); a los escritos procesales de una institución presentados en un procedimiento judicial (STJUE de 21 de septiembre de 2010, asuntos acumulados C-514/07 P, C-528/07 P y C-532/07 P); a los documentos de un procedimiento de incumplimiento en la fase administrativa previa (STJUE de 14 de noviembre de 2013, asuntos acumulados C-514/11 P y C-605/11 P); a los documentos de un procedimiento de aplicación del artículo 101 TFUE (STJUE de 27 de febrero de 2014, asunto C-365/12 P); a las ofertas de los licitadores en un procedimiento de contratación pública ante la solicitud de otro licitador (STJUE de 29 de enero de 2013, asuntos acumulados T-339/10 y T-532/10); a los documentos obrantes en una investigación de la Oficina Europea contra el Fraude (STJUE de 26 de mayo de 2016, asunto T-110/15); a los documentos de un procedimiento de abuso de posición dominante concluso (STJUE de 28 de marzo de 2017, asunto T-210/15); y, a los documentos de un procedimiento "EU Pilot" (STJUE de 11 de mayo de 2017, asunto C-562/14 P). 
garantizar el buen funcionamiento de los procedimientos y el respeto de los intereses en juego ${ }^{88}$. El principio de transparencia exige interpretar estas excepciones de manera restrictiva ${ }^{89}$.

Particular interés presenta la reciente STJUE de 22 de enero de 2020 (asunto C175/18 P). La Sentencia afirma que la utilidad de estas presunciones reside en posibilitar que la Administración deniegue la divulgación sin necesidad de realizar una ponderación concreta e individualizada de cada documento ${ }^{90}$, por ello deben referirse a "categorías de documentos de igual naturaleza" 91 . La Administración debe razonar la existencia efectiva de la presunción de confidencialidad ${ }^{92}$.

Ante una presunción de confidencialidad, la Administración puede decidir ponderar los intereses en conflicto o denegar la información, justificando y

${ }^{88}$ SSTJUE de 25 de septiembre de 2014 (asunto T-306/12); de 5 de febrero de 2018 (asuntos T235/15, T-718/15 y T-729/15); y, de 4 de octubre de 2018 (T-128/14).

89 SSTJUE de 16 de julio de 2015 (asunto C-280/11 P); de 5 de febrero de 2018 (asuntos T235/15, T-718/15 y T-729/15); y, de 4 de octubre de 2018 (T-128/14). En sintonía con esta doctrina, la STJUE de 4 de octubre de 2018 (T-128/14) afirma que “(...) en la medida en que la posibilidad de recurrir a presunciones generales no solamente tiene por efecto socavar el principio fundamental de transparencia (...), sino que, además, y necesariamente, limita en la práctica el acceso a los documentos en cuestión, el recurso a tales presunciones debe estar fundado en razones sólidas y convincentes".

90 La STJUE de 22 de enero de 2020 (asunto C-175/18 P) se expresa en los siguientes términos: "El objetivo de estas presunciones reside, así, en la posibilidad de que la institución, órgano u organismo de la Unión de que se trate considere que la divulgación de determinadas categorías de documentos perjudica, en principio, al interés protegido por la excepción que invoca, basándose en dichas consideraciones de carácter general, sin tener la obligación de examinar concreta e individualmente cada uno de los documentos solicitados (...). No obstante, una institución, órgano u organismo de la Unión no está obligado a basar su decisión en tal presunción general, sino que siempre podrá optar por llevar a cabo un examen concreto de los documentos a que se refiere la solicitud de acceso y facilitar la correspondiente motivación (...). De ello se sigue que el recurso a las presunciones generales de confidencialidad no es más que una simple facultad de la institución, órgano u organismo de la Unión en cuestión, que siempre conserva la posibilidad de efectuar un examen concreto e individual de los documentos que se trate para determinar si están protegidos, en todo o en parte, por una o varias de las excepciones contempladas en el artículo 4 del Reglamento $n^{\circ}$ 1049/2001". En similar sentido se expresa la STJUE de 4 de septiembre de 2018 (asunto C-57/16).

${ }^{91}$ SSTJUE de 1 de julio de 2008 (asuntos acumulados C-39/05 P y C-52/05 P); de 29 de junio de 2010 (asunto C-139/07); de 17 de octubre de 2013 (asunto C-280/11 P); de 14 de noviembre de 2013 (asuntos C-514/11 P y C-605/11 P); de 27 de febrero de 2014 (asunto C-365/12 P); de 5 de febrero de 2018 (asuntos T- 235/15, T-718/15 y T-729/15); y, de 4 de octubre de 2018 (T128/14).

92 La STJUE de 4 de octubre de 2018 (T-128/14) establece que "(...) para poder oponer frente a la demandante una presunción general de no divulgación de los documentos solicitados, la Comisión debería haber explicado las razones por las que era necesaria esa presunción para garantizar tanto el correcto funcionamiento del procedimiento de que se trata en el caso de autos (...) como el logro de los objetivos de este". 
amparándose en la presunción. El análisis de las circunstancias concurrentes puede obedecer a que la Administración lo considere oportuno o a que el solicitante demuestre la conveniencia de la ponderación ${ }^{93}$.

Las presunciones de confidencialidad no son incontestables. Pero ello no implica que no sean útiles, pues no podrá difundirse activamente información presuntamente confidencial (art. 6 de la Ley 27/2006). Únicamente procederá su difusión cuando se presente una solicitud de acceso y ésta sea estimada tras la debida ponderación ${ }^{94}$.

El titular del secreto deberá acreditar la existencia de la presunción, que deberá preverse de manera suficientemente clara en la normativa sectorial ${ }^{95}$.

\section{CONCLUSIONES}

El art. 13.2.d) de la Ley 27/2006 reconoce "los datos confidenciales de carácter comercial o industrial" como excepción al derecho de acceso a la información ambiental. La simple lectura del precepto evidencia dos problemas interpretativos que dificultan su aplicación.

El primer problema exige concretar qué debe entenderse por "datos confidenciales de carácter comercial o industrial". Este término debe reconducirse al otro más genérico, y comúnmente utilizado por la doctrina mercantilista, de "secreto empresarial".

\footnotetext{
${ }^{93}$ La existencia de una presunción no impide que el interesado pruebe que un determinado documento no se encuentra amparado por la presunción (SSTJUE de 21 de septiembre de 2010, asuntos acumulados C-514/07 P, C-528/07 P y C-52/05 P; y de febrero de 2018, asuntos T235/15, T-718/15 y T-729/15).

94 Como afirma la STJUE de 23 de noviembre de 2016 (asunto C-442/14) "la presunción que establece el apartado 2.de este artículo permite a la autoridad competente considerar que la información presentada por el solicitante de una autorización de comercialización que está comprendida en esta disposición sea, en principio, confidencial y que no pueda ser puesta a disposición del público si no se presenta ninguna solicitud de acceso a esta información sobre la base de la Directiva 2003/4".

${ }^{95}$ La STGUE de 13 de enero de 2017 niega la existencia de una presunción general de confidencialidad en el Reglamento REACH puesto que no regula un régimen de divulgación de información y confidencialidad específico. La STJUE de 5 de febrero de 2018 (asunto T-235/15), refiriéndose al Reglamento no 726/2004 del Parlamento Europeo y del Consejo, de 31 de marzo de 2004, por el que se establecen procedimientos comunitarios para la autorización y el control de los medicamentos de uso humano y veterinario y por el que se crea la Agencia Europea de Medicamentos, negó que el legislador pretendiese construir un "régimen específico de acceso a los documentos que deba interpretarse en el sentido de que se presume la confidencialidad", por el mero hecho de establecer un "régimen de publicación proactiva mínima de información".
} 
La aprobación de la necesaria Ley $1 / 2019$, de Secretos Empresariales, clarifica la cuestión al positivizar la definición de "secreto empresarial". Esta norma no supone, ni pretende suponer, un reconocimiento genérico de confidencialidad de los datos empresariales.

El segundo problema se centra en analizar cuáles son los presupuestos que exige el citado art. 13.2.d) para denegar una solicitud de acceso, amparándose en el secreto empresarial. Estos presupuestos son los siguientes:

En primer lugar, la finalidad de la denegación debe ser la protección del secreto. Es un interés legítimo que las empresas quieran proteger la información relevante sobre la que basan sus ventajas competitivas.

En segundo lugar, la legislación ambiental debe reconocer el carácter confidencial de los documentos solicitados. Dicha confidencialidad debe establecerse de forma clara en una norma con rango de ley, y no en un contrato.

En tercer lugar, la Administración debe determinar si la divulgación afecta negativamente al secreto y, en ese caso, ponderar los intereses en conflicto. Es el titular del secreto quien soporta la carga de probar dicha afectación negativa, que debe interpretarse restrictivamente. Posteriormente, el órgano administrativo debe ponderar el interés público que justifica la divulgación y el interés privado que ampara la denegación. Dichos intereses son "conceptos globales" por lo que es posible que coexistan más de un interés público y/o privado, que deberán ser tenidos en cuenta.

La ponderación es un razonamiento debido del órgano administrativo. El legislador no puede establecer mecanismos que impidan dicho análisis comparado de las circunstancias concurrentes.

La existencia de presunciones generales de confidencialidad incide en la ponderación de los intereses en juego. El establecimiento de una presunción iuris et de iure de publicación, como la del art. 13.5 de la Ley 27/2006, impide denegar información solicitada sobre emisiones, aunque afecte negativamente al secreto empresarial. Si la presunción establece la confidencialidad de la información, el TJUE entiende que la Administración puede denegar la solicitud amparándose en dicha presunción y justificando su existencia respecto a cada 
concreto documento. No obstante, nada le impide ponderar efectivamente los intereses en juego y decidir, en su caso, divulgar la información.

\section{BIBLIOGRAFÍA}

AGUDO GONZÁLEZ, J., "El derecho de acceso a la información en materia de medio ambiente en la jurisprudencia española", Revista de Derecho Urbanístico y Medio Ambiente, № 181, 2000.

ALONSO GARCíA, E., "La participación de los individuos en la toma de decisiones relativas al medio ambiente en España", Revista Española de Derecho Administrativo, №. 61, 1989.

ARROYO JIMÉNEZ, L., "Ponderación, proporcionalidad y Derecho Administrativo", en ORTEGA ÁLVAREZ, L.I. y DE LA SIERRA MORÓN, S. (coords.), Ponderación y Derecho Administrativo, Marcial Pons, 2009.

BAÑO LEÓN, J.M., "Declaración responsable y derechos de terceros. El lado oscuro de la llamada better regulation", Revista Española de Derecho Administrativo, ํo. 167, 2014, págs. 23 y ss.

CARBAJO CASCÓN, F., "Violación de secretos, inducción y aprovechamiento de la infracción contractual e infracción de normas", en GARCÍA-CRUCES GONZÁLEZ, J. (coord.), Tratado de Derecho de la Competencia y de la Publicidad, Tomo II, Tirant lo Blanch, 2014.

CASADO CASADO, L., "EI derecho de acceso a la información ambiental previa solicitud", en PIGRAU SOLÉ, A. (Dir.), Acceso a la información, participación pública y acceso a la justicia en materia de medio ambiente: diez años del Convenio de Aarhus, Atelier, 2008.

- "El derecho de acceso a la información ambiental a través de la jurisprudencia", Revista de Administración Pública, oㅜ178, 2009, págs. 281 a 322.

- "El acceso a la información ambiental en España: luces y sombras", Derecho PUCP, ํo 70, 2013, págs. 241 a 278.

- "El acceso a la información ambiental en España: situación actual y perspectivas de futuro", Revista Aragonesa de Administración Pública, ํㅡ 53, 2019, págs. 99 y ss. 
DÍEZ PICAZO, L., La doctrina de los actos propios: un estudio crítico sobre la jurisprudencia del Tribunal Supremo, Civitas, Cizur Menor, 2014.

ESTEVE PARDO, J., "De la policía administrativa a la gestión de riesgos", Revista Española de Derecho Administrativo, no. 119, 2003, págs. 323 y ss.

- "La deconstrucción de las fórmulas de intervención administrativa: de la aplicación de la Ley a la contractualización", Revista Vasca de la Administración Pública, № 99-100, 2014, págs. 1231-1239.

FERNÁNDEZ DE CÓRDOBA, S., Derecho de patentes e investigación científica, Tirant lo Blanch, 1996.

FERNÁNDEZ RAMOS, S., El derecho de acceso a los documentos administrativos, Marcial Pons, 1997.

- El derecho de acceso a la información medioambiental, Thomson ReutersAranzadi, 2009.

- "Información ambiental y transparencia pública", Revista Aranzadi de Derecho Ambiental, no 39, 2018, págs. 19 y ss.

FERNÁNDEZ RODRÍGUEZ, T.R., "El Medio Ambiente en la Constitución Española", Documentación Administrativa, oo 190, 1981.

FERNÁNDEZ TORRES, J.R., "Regímenes de intervención administrativa: autorización, comunicación previa y declaración responsable", Revista Catalana de Dret Public, ํo. 42, 2011, págs. 96 y ss.

GARCÍA DE ENTERRÍA, E., "Principios y modalidades de la participación ciudadana en la vida administrativa", en GÓMEZ-FERRER MORANT, R. (coord.), Libro homenaje a José Luis Villar Palasí, Civitas, 1989, pág. 443 y ss.

GARCÍA MACHO, R., Derecho administrativo de la información y administración transparente, Marcial Pons, 2010.

GARCÍA URETA, A., "Perspectivas sobre el derecho de acceso a la información sobre el ambiente: un repaso a la Directiva 90/313/CEE", Revista de Derecho Ambiental, № 13, 1994. 
GARCÍA VIDAL, Á., "El contenido del derecho de «obtentor» de una variedad vegetal (luces y sombras del Convenio de la UPOV)", Revista de Derecho Mercantil, no 279, 2011, pág. 99 y ss.

GÓMEZ SEGADE, J.A., El secreto industrial (know-how). Concepto y protección, Tecnos, 1974.

KRAMER, L., 'Citizens rights and administrations' duties in environmental matters: 20 years of the Aarhus Convention", Revista Catalana de Dret Ambiental, no 9, 2018, págs. 5 a 11.

LOZANO CUTANDA, B. y GUTIÉRREZ-ALNIZ CONRADI, F., Examen de la nueva Ley de acceso a la información, participación pública y acceso a la justicia en materia de medio ambiente, Consejo General del Poder Judicial, 2008.

MASSAGUER FUENTES, J., El contrato de licencia de know-how, Librería Bosch, 1989.

- "Aproximación sistemática general al Derecho de la competencia y de los bienes inmateriales", Revista general de derecho, no 544-545, 1990.

- "De nuevo sobre la protección jurídica de los secretos empresariales: a propósito de la Ley 1/2019, de 20 de febrero, de Secretos Empresariales", Actualidad Jurídica Uría Menéndez, no 51, 2019, págs. 46-70.

MUÑOZ MACHADO, S., "Las concepciones del Derecho administrativo y la idea de participación en la Administración", Revista Administración Pública, № 84, 1977, pág. 519 y ss.

- Tratado de Derecho Administrativo y Derecho Público General, Tomo I (Historia de las instituciones jurídico-administrativas 1), Civitas, 2015, pág. 61 y ss.

PAREJO ALFONSO, L., "La Directiva Bolkestein y la «Ley paraguas»: ¿Legitima el fin cualesquiera medios para la reconversión del estado "autoritativo»?", Revista Española de Derecho Europeo, ํo. 32, 2009.

PORTELLANO DÍEZ, P., "Protección de la información no divulgada", en IGLESIAS PRADA, J.L. (coord.), Los derechos de propiedad intelectual en la Organización Mundial del Comercio: el Acuerdo sobre Aspectos de los Derechos 
de Propiedad Intelectual relacionados con el Comercio, Centro de Estudios para el fomento de la Investigación, 1997.

PORTER, M.E., La ventaja competitiva de las naciones, Plaza \& Janés, 1991.

QUERALT JIMÉNEZ, J.J., "La inviolabilidad domiciliaria y los controles administrativos. Especial referencia a la de las empresas", Revista Española de Derecho Constitucional, ํㅜ 30, 1990, págs. 41 y ss.

RAZQUIN LIZARRAGA, J.A., y RUIZ DE APODACA ESPINOSA, A., Información, participación y justicia en materia de medio ambiente. Comentario sistemático a la Ley 27/2006, de 18 de julio, Aranzadi, 2007.

RAZQUIN LIZARRAGA, M.M., La confidencialidad de los datos empresariales en poder de las Administraciones Públicas (Unión Europea y España), lustel, 2013.

RAZQUIN LIZARRAGA, J.A., "El acceso a la información en materia de medio ambiente en España: balance y retos de futuro", Revista Catalana de Dret Ambiental, vol. 9, ㄲo 1, 2018.

REVUELTA PÉREZ, I., El control integrado de la contaminación en el Derecho Español, Marcial Pons, 2003.

- "La participación de los ciudadanos en el control integrado de la contaminación", en ESTEVE PARDO, J. (coord.), Derecho del medio ambiente y de la Administración Local, Fundación Democracia y Gobierno Local, 2006.

RODRÍGUEZ FONT, M., Régimen de comunicación e intervención ambiental. Entre la simplificación administrativa y la autorregulación, Atelier, 2003.

RUIZ MIGUEL, C., La configuración constitucional del derecho a la intimidad, Tecnos, 1995.

SAINZ MORENO, F., "Secreto e información en el Derecho Público", en MARTíN-RETORTILLO BAQUER, S., Estudios sobre la Constitución Española. Homenaje al profesor Eduardo García de Enterría, vol. 3, Civitas, 1991.

SÁNCHEZ MORÓN, M., "La participación del ciudadano en la Administración Pública", Revista de Administración Pública, № 89, 1980, pág. 171 y ss. 
- "El derecho de acceso a la información en materia de Medio Ambiente", Revista de Administración Pública, № 137, 1998, págs. 31 a 56.

SANTAMARÍA PASTOR, J.A., "La actividad de la Administración", en Comentario sistemático a la Ley de Régimen Jurídico de las Administraciones Públicas y del Procedimiento Administrativo Común, Carperi, pág. 142, 1993.

SCHMIDT-ASSMANN, E., La teoría general del derecho administrativo como sistema: objeto y fundamentos de la construcción sistemática, Marcial Pons, 2003.

SUÑOL LUCEA, A., El secreto empresarial: un estudio del artículo 13 de la Ley de Competencia Desleal, Civitas Thomson-Reuters, 2009.

TRIAS PRATS, B., "Veinticinco años de acceso a la información ambiental en Italia: de la ley 349/1986 a la Directiva Inspire", en Revista de Administración Pública, № 188, 2012.

VAREA SANZ, M., El modelo de utilidad: Régimen jurídico, Aranzadi, 1996. 